\title{
Políticas comunicacionales, representaciones mediáticas y legitimidad judicial. Un estudio de caso sobre la Corte Suprema de la República Argentina
}

Communication Policies, Media Representations and Judicial Legitimacy. A Case Study on Argentina's Supreme Court

Valentín Thury Cornejo. Universidad Austral (Argentina)

Recibido: 19-XI-2009 - Aceptado: 18-I-2010

Resumen:

El presente trabajo analiza el complejo rol que los medios de comunicación asumen en la conformación de la imagen de los tribunales de justicia y, mediatamente, en su legitimidad. A partir de un estudio de caso sobre la Corte Suprema de la República Argentina, se intentan identificar los mecanismos culturales que entran en juego en la construcción de los imaginarios sociales respecto de la actuación de la Justicia. Para ello, se analiza el discurso de los tres principales diarios y se reconstruye la lógica periodística que lo informa, confrontándola con la lógica jurídica que guía la actuación del tribunal.

Palabras clave:

Política comunicacional, Poder judicial, Legitimidad, Medios de Comunicación, Representaciones sociales.

Abstract:

This work analyzes the complex role of mass media in building Court's public image and, indirectly, in its legitimacy. Through a case study of the Supreme Court of Argentine Republic, the article identifies the cultural mechanisms relevant for the construction of social imaginaries regarding the performance of Judicial Power. To do this, the three main argentine newspapers are analyzed and the newsmaking rationale is reconstructed, being the latter confronted with the underlying principle that guides the conduct of the court.

Key Words:

Communication Policy, Courts, Legitimacy, Mass Media, Social Representations. 


\section{Introducción}

En su discurso en la Segunda Conferencia Nacional de Jueces, realizada en la provincia argentina de Salta en 2007, el presidente de la Corte Suprema de Justicia, Ricardo L. Lorenzetti, llamó a reconstruir institucionalmente la judicatura, instando a los jueces presentes a revitalizar los "deteriorados vínculos entre el poder judicial y la sociedad” (Lorenzetti, 2007). El magistrado se hacía así cargo de la crisis de confianza por parte de la ciudadanía, que había llevado a que el Poder Judicial generara algún tipo de aprobación en solamente un $19 \%$ de la población, frente a un $48 \%$ de los medios, un $42 \%$ de la Iglesia y un $26 \%$ del empresariado argentinos (PNUD 2005). Esta situación obedecía, respecto a la Corte Suprema de Justicia, a un debilitamiento institucional que se expresó en la falta de estabilidad de su conformación, los cambios en el número de sus integrantes, la falta de debate público en la designación de los jueces, la extensión desmedida de las competencias del tribunal y, en general, a la falta de transparencia en su actuación (Carrió, 1996; Smulovitz, 1995). El punto final de ese proceso estuvo dado por la actuación de la Corte Suprema durante los 10 años de gobierno de Carlos Menem (1989-1999), donde el tribunal acompañó muchas de sus políticas a pesar de las tachas de inconstitucionalidad que pesaban sobre ellas (Kapiszewski, 2006). La pérdida de legitimidad institucional de la Corte llevó a un proceso de renovación institucional, por medio del cual siete de sus nueve miembros -nombrados de modo vitalicio- habían dejado sus puestos en un período de tres años y un nuevo tribunal de siete miembros quedó conformado ${ }^{1}$. La frase de Lorenzetti encarnaba así el sentir de la "nueva Corte", llamada a reconstruir su legitimidad de cara a la ciudadanía argentina.

En esta tarea, el tribunal ha sido exitoso. A través de una serie de reformas en sus procedimientos y organización, nuevos mecanismos de relación con la sociedad civil y la resolución de casos de alto impacto público se ha "instalado socialmente como una actora con peso institucional propio" (Litvachky y Zayat, 2007). Uno de los baluartes de esas reformas ha sido una renovada política comunicacional, que dio lugar a la creación del Centro de Información Judicial (CIJ), al creciente uso de los comunicados de prensa y a la accesibilidad de los ministros frente a los periodistas, lo cual se ha traducido en la casi cotidiana aparición de algunos de

\footnotetext{
Esta profunda crisis de legitimación motivó una creciente presión ciudadana, que se hizo patente en las protestas de los ahorristas para la resolución de los problemas derivados del "corralito". Haciéndose eco de esta situación -y continuando el frustrado intento del anterior presidente Duhalde-, Kirchner promovió el juicio político a cinco de los miembros de la Corte Suprema. Para septiembre de 2005, dos de ellos habían sido removidos (Moliné O’Connor y Boggiano), otros tres habían renunciado (Nazareno, Vázquez y López) y otro se había jubilado (Belluscio). Habiendo Duhalde llenado con el ministro Maqueda la vacante producida por la renuncia de Bossert, Kirchner designó a cuatro de los actuales integrantes (Zaffaroni, Lorenzetti, Highton y Argibay). Luego de un período de indefinición ante la demora del Ejecutivo en proponer los dos candidatos para llenar las vacantes existentes, el Congreso sancionó, a fines del año 2006, la ley 26183 por la cual se redujo temporariamente el número de integrantes a siete con la prospectiva de que quede luego fijado definitivamente en los cinco originales.
} 
ellos en los medios de comunicación. ¿Cuál ha sido la idea fuerza de esta política? La lógica detrás de la multiplicidad de acciones comunicativas que el tribunal ha desplegado ha sido la de pasar de una cultura del sigilo y del secreto judicial a una política de mayor transparencia, y para ello ha adoptado, frente a su tradicional posición pasiva, una actitud proactiva respecto de la comunicación (Lorenzetti, 2007). A través de esta política, la Corte Suprema intentó acercar la institución a la gente, que la percibía "como una institución lejana", cuyo "funcionamiento es difícil de conocer" (ADC, 2008: 46). La transparencia buscada se concretó en la publicación de todas las sentencias del Tribunal en su página web, la publicidad de la circulación de los expedientes y de los casos trascendentes en trámite, la institución del amicus curiae y la celebración de audiencias públicas, entre otras medidas. Este valor de transparencia se tradujo, asimismo, en una apertura de la Corte a los medios de comunicación, quienes supuestamente debían amplificar la información judicial para que esta sea receptada por el gran público.

El objetivo del presente trabajo es aportar elementos que ayuden a evaluar adecuadamente las implicaciones que tienen políticas comunicacionales como la seguida por la Corte Suprema de Argentina. En concreto, ¿qué beneficios y riesgos implican, para la actividad judicial, la relación con los medios de comunicación? Si bien es claro que existe un derecho de la sociedad a la información, también lo es que hay un derecho correlativo a una función judicial efectiva. Las tensiones entre uno y otro se juegan en las políticas de comunicación que los tribunales diseñan, anudados en la lucha por la legitimidad para el ejercicio de sus funciones. Los jueces necesitan construir la legitimidad que es la base de su poder para "decir el derecho", o sea, para la jurisdicción -juris dictio. Su poder tiene una base constitucional y legal, pero su autoridad efectiva depende de la vigencia en la esfera pública. Por este motivo, la pregunta sobre los procesos sociales que hacen a esa construcción de legitimidad y que nos formuláramos con anterioridad (Thury Cornejo, 2008; 2009a), vuelve hoy focalizada en el rol que los medios de comunicación tienen en esa compleja trama. Para Max Weber, como sabemos, la legitimidad se edifica sobre una creencia que motiva la obediencia a la autoridad (Weber, 1979). Es decir, que cuando hablamos de legitimidad, no estamos ante un proceso mensurable cuantitativamente sino ante un fenómeno de índole cultural, una creencia. Este hecho tiene una consecuencia teórica fundamental respecto a las preguntas que acabamos de formular ya que los procesos culturales, como se ocupa de resaltar Suchman (1995), "se apoyan fuertemente en la comunicación”. Por este motivo, ahondar en el concepto de legitimidad nos obliga a analizar los mecanismos de construcción cultural de estas creencias y las dinámicas comunicativas implicadas, tanto teórica como empíricamente.

Este artículo no pretende responder de forma completa a las preguntas formuladas sino aportar algunos elementos que nos permitan profundizar en nuestros conocimientos sobre las dinámicas de los procesos de 
legitimación, en particular vinculándolos con los mecanismos comunicativos a través de los cuales esa legitimidad se construye, mantiene o pierde. En ese esquema, los medios de comunicación asumen un papel central en la conformación de las representaciones sociales sobre las cuales la legitimidad se edifica, y la primera parte del escrito se dedicará a fundamentar teóricamente este punto. Ello servirá de introducción al núcleo de este artículo, configurado por un estudio de caso en el que analizaremos la cobertura periodística del conflicto planteado en marzo del 2007 entre el entonces presidente de la Nación Néstor Kirchner y la Cámara de Casación Penal, episodio en el que la Corte terció a través de la emisión de un comunicado institucional. El intercambio de ideas entre estos protagonistas respecto de los juicios sobre violaciones a los derechos humanos -explicado con detalle en el punto 2.1- tuvo una gran repercusión periodística y se convirtió en un acontecimiento mediático que llegó a la primera plana de los principales medios locales durante varios días. Esa situación, a la que nos referiremos en adelante como "caso Bisordi” -nombre del presidente de la Cámara de Casación Penal argentina- servirá de escenario para analizar las lógicas actuantes y la forma en que los medios de comunicación representan a la Corte Suprema. Analizando en concreto el tratamiento que la prensa le dio al caso Bisordi, entonces, podremos incorporar nuevas dimensiones de análisis que nos permitan evaluar las políticas de comunicación de los tribunales de justicia, sus límites y sus efectos a largo plazo.

\section{Legitimidad, medios de comunicación y representaciones sociales}

¿Por qué es tan importante la legitimidad? En términos generales, la legitimidad aparece como una condición sociológica de la permanencia institucional ya que "el orden político es más probable que persista cuando el régimen puede establecer su autoridad "adentro" del individuo en lugar de "externamente" a través de la amenaza del uso de la fuerza o los incentivos para la recompensa material” (Grafstein, 1981: 51). Si esto es así para la estructura de poder en general, lo es aún más para el Poder Judicial ya que como dijera Hamilton en los albores de la fundación norteamericana, la Corte, por carecer del recurso de la fuerza para aplicar sus decisiones y del presupuesto para garantizar su funcionamiento, es el poder más débil del esquema tripartito en que se estructura el Estado moderno (Hamilton, Madison y Jay, 1994). En consecuencia, si podemos afirmar que todo poder para ser obedecido de forma estable debe ser percibido como legítimo, en el caso de la Corte Suprema esa característica asume un carácter central (Perry, 1999). Ahora bien, ¿̇a qué nos referimos cuando hablamos de legitimidad? Adoptando como base de nuestra argumentación la definición de Suchman, diremos que:

La legitimidad es una percepción o suposición generalizada de que las acciones de una entidad son deseables, correctas o apropiadas dentro de un sistema socialmente construido de normas, creencias y definiciones (1995: 574). 
De modo que, continúa este autor,

La legitimidad es una percepción o suposición en el sentido en que representa una reacción de los observadores a la organización como ellos la ven; por lo tanto, la legitimidad es poseída objetivamente, pero creada subjetivamente. La legitimidad es socialmente construida en el sentido de que refleja una coherencia entre las conductas de la entidad legitimada y las creencias compartidas (o presumiblemente compartidas) de algún grupo social" (1995: 574).

Esta última afirmación es de particular importancia porque nos señala los dos puntos de referencia en la relación de legitimación: las conductas de la entidad y las creencias compartidas. La legitimidad va a depender fuertemente de las concepciones sociales acerca del papel que debe cumplir la organización, ya que ello va a determinar el patrón de medida de su conducta y la consiguiente creencia en su adecuación. La actuación de un ente, entonces, se confronta con las expectativas sobre su conducta, con la idea sobre lo que aquél tiene que hacer y de allí surge la convicción acerca de su legitimidad o ilegitimidad. En el caso del Derecho y las instituciones jurídicas, esta creencia asume una forma pasiva y receptiva que tiende a generar obediencia (de Páramo Argüelles, 2000). Por ello, estas expectativas suelen estar directamente relacionadas con una legitimidad de tipo cognitivo, ello es en la aceptación que una conducta o institución tiene como "necesaria o inevitable basada en un sustrato cultural que se da por supuesto" (Suchman, 1995: 582).

Justamente, el proceso de consolidación de instituciones se basa en la conformación de un núcleo “dado por supuesto" y la consiguiente adecuación de las conductas en ese sentido (Phillips, Lawrence y Hardy, 2004). En esta situación, "cada individuo está motivado a cumplir porque de otra manera sus acciones y las de otros en el sistema no se pueden entender" (Zucker, 1999). Aquí se encuentra ausente la evaluación de las actividades de la entidad: no hay una actividad del sujeto en la que juzga la pertinencia de la conducta con algún tipo de parámetro (por los resultados, por los procedimientos seguidos, o por la confianza en los ejecutantes) sino que la conducta seguida se vive como la única posible. Por este motivo, la legitimidad de tipo cognitivo representa, para Suchman, "al mismo tiempo, la más sutil y la más poderosa fuente de legitimidad identificada hasta la fecha. Si las alternativas son impensables, los desafíos se transforman en imposibles, y la entidad legitimada se convierte en inexpugnable" (1995: 583). La legitimidad cognitiva asume un fuerte contenido cultural, al basarse en presupuestos implícitos no sujetos a discusión. Por ese motivo, muchos autores han traducido la fuerte legitimidad institucional de la Corte estadounidense en términos de mito (Casey, 1972; Corwin, 1936; Lerner, 1937). Esta idea del fundamento mítico de la legitimidad de la Corte se relaciona con la idea de lo "dado por supuesto" justamente porque el mito remite a una fuente de legitimidad que no debe ser explicada, argumentada, ni puede ser eva- 
luada, al menos en términos racionales. Al mismo tiempo, como explica Suchman, es una referencia sutil y, en muchos aspectos, inasible.

Una aproximación cultural al concepto de legitimidad judicial implica, pues, dos afirmaciones: una, que la legitimidad de un tribunal se juega en el terreno largoplacista y difuso de lo "dado por supuesto", y dos, que los medios de comunicación son actores fundamentales en la creación de esos marcos de referencia. Para fundamentar estos postulados nos ayudaremos de dos conceptos, proveniente uno de la psicología social -“representaciones sociales" (Moscovici y Markova, 1998)- y el otro de la sociología de la cultura, "discurso de la sociedad civil" (Alexander, 2006). Las representaciones sociales son "construcciones simbólicas individuales y/o colectivas a las que los sujetos apelan o crean para interpretar el mundo, para reflexionar sobre su propia situación y la de los demás y para determinar el alcance y la posibilidad de su acción histórica" (Vasilachis de Gialdino, 2007). Estas representaciones sociales son el resultado de procesos intersubjetivos que se dan en la práctica y que involucran aspectos cognitivos y emocionales (Raudsepp, 2005). En este sentido, se alejan de una mera idea intelectual e individual para configurarse como el sustrato de pensamiento que nutre a un grupo social. Alexander se refiere a este entramado de significaciones como "discurso de la sociedad civil", describiéndolo como "un terreno de conciencia estructural y socialmente establecida, una red de entendimientos que crea estructuras de sentimientos que permean la vida social y que corren justo por debajo de la superficie de instituciones estratégicas y élites auto-concientes” (2006: 54).

Sin ánimo de entrar en una discusión conceptual sobre estas categorías, nos interesa destacar que estas representaciones o discurso son de construcción social, se sitúan a un nivel supraindividual y exceden el marco de la mera cognición. Al mismo tiempo, destaca Murray (2002: 667) que es "a través del proceso social de narración que estas representaciones sociales son creadas y recreadas". Es justamente esta característica la que las conecta directamente con los medios de comunicación. El hombre, al decir de Gerbner (1998), es la única especie que vive en un mundo edificado por las historias que cuenta. Esas historias fueron siempre hechas en casa, artesanalmente, inspiradas en la comunidad y, lo más importante, contadas cara a cara. Con la aparición de la imprenta, sin embargo, esta relación comienza a mediatizarse y a industrializarse. Este proceso se acelera con la llegada de las formas electrónicas de comunicación, que crean nuevas formas de acción e interacción (Thompson, 2005: 32) en las que el entorno mediático se convierte en la fuente primaria del conocimiento y sentido común (Couldry, 2004). De este modo, hoy en día, "los públicos son amplios agregados de gente que comparte alguna conciencia común acerca de cómo las cosas funcionan, qué son las cosas y qué debería ser hecho, pero nunca se encuentran cara a cara. En el pasado, esto no había sido nunca posible" (Gerbner, 1998: 176). Estas afirmaciones muestran la enorme 
importancia que los medios de comunicación tienen en los procesos de legitimación, ya que al actuar sobre las creencias compartidas y modelar las representaciones sociales, contribuyen a formar la base sobre la que se van a emitir los juicios -explícitos o implícitos- de legitimidad.

Esto significa no sólo que los medios van a ser los grandes socializadores políticos (Graber, 2002), sino que también van a ser el foro en el cual se van a dar las disputas para la conformación del discurso social. Al decir de Thompson, "la visibilidad mediatizada no es solamente un vehículo a través del cual aspectos de la vida política y social son traídos a la atención de los otros, sino que se ha transformado en el medio principal en que las luchas políticas y sociales son articuladas y llevadas a cabo" (Thompson, 2005: 49). Es tal la fuerza del contexto mediático en el que nos movemos, que algunos autores sostienen que existe una distancia objetiva que media entre el círculo de decisiones reales, al que los actores políticos y jurídicos tienen acceso directo, y el círculo de espectadores, "para quienes la política es una serie de imágenes en la mente, ubicadas allí por las noticias de TV, diarios, revistas y discusiones” (Edelman, 1967: 5). Esa brecha genera, para los que carecen de contacto directo, una visión que se basa en cuestiones emocionales y simbólicas más que en los datos concretos de actuación del órgano y con ello favorece el predominio de una imagen mítica.

Resumiendo lo que hemos dicho hasta aquí, los medios ejercen de nexo -en la mayor parte de los casos, monopólico- entre el público y la realidad. De esta forma, la realidad es, en gran medida, la que nos dicen los medios y nuestros marcos cognitivos están fuertemente condicionados por sus mensajes. A este rol conformador de nuestro sentido común, los medios le agregan la característica de ser una parte ineludible de la esfera pública contemporánea. Por ello, son escenario de las luchas de poder sobre la asignación de sentido (Mellucci, 2001) o, en otras palabras, son el espacio en el que se dan la mayoría de las interacciones sociales que llevan a la conformación de las representaciones vigentes. Finalmente, la actividad de los medios genera, justamente por su carácter distanciado de la realidad concreta, una tendencia a la legitimación basada en la imagen más que en la evaluación detallada y concreta de las actividades públicas. La expresión superlativa de este fenómeno está constituida por la llamada "sociedad del espectáculo"2.

Habiendo establecido el significado de la legitimidad institucional de la Corte Suprema como una aceptación de la necesidad o inevitabilidad de esta organización, que se basa en un sustrato cultural común (Johnson, Dowd y Ridgeway, 2006), hemos visto la trascendental influencia que los medios tienen en esa

2 El término "sociedad del espectáculo" fue acunado por Guy Debord y su escuela situacionista. Si bien remitimos en el texto a ese concepto, pretendemos desgajarlo de la particular impronta ideológica que ese movimiento le dio. De manera más genérica, nos referimos a los fenómenos que hemos descripto en extenso en otros trabajos (Thury Cornejo, 2009b) y que hacen que la dinámica mediática favorezca formas "personalizadas" de política (Patterson, 1994) donde "los políticos se convierten en estrellas, la política se convierte en una serie de espectáculos y los ciudadanos se transforman en espectadores” (Street, 2004: 441). 
construcción social. En el caso de la Corte Suprema de Estados Unidos, su posición simbólica tiene hondas raíces en los marcos de referencia de la población, situación que ha hecho que se hable de una religión civil americana (Bellah, 1967) de la cual la Corte sería uno de sus sacerdotes supremos (Lerner, 1937). Como hemos mostrado en trabajos anteriores (Thury Cornejo, 2009a), esta situación le permite a la Corte Suprema americana mantener una posición distante de los medios, justamente porque no depende de ellos para construir su legitimidad y elige no arriesgar su capital simbólico en esa relación ${ }^{3}$. Aun cuando la relación entre legitimación, procesos socio-culturales y medios de comunicación es semejante, el caso argentino nos plantea un escenario diferente al americano. Distinto es el caudal de legitimación con el que contaba la Corte y también lo es, como hemos señalado en la introducción, la política de relación con los medios que ha emprendido. Dejando de lado el análisis acerca de la conveniencia o no del enfoque adoptado por la Corte Suprema argentina, exploraremos a través del estudio en profundidad del caso Bisordi, cómo, en concreto, los medios actúan sobre las representaciones sociales acerca de la Corte y las implicaciones que esta dinámica tiene en los procesos de legitimación que hasta ahora hemos repasado de forma teórica.

\section{Corte Suprema y medios en Argentina}

\section{1. Los hechos del caso Bisordi}

En su discurso de apertura de las sesiones ordinarias del Congreso de la Nación, el día 1 de marzo de 2007, el entonces presidente argentino Néstor Kirchner (2003-2007) hizo un fuerte llamamiento al Poder Judicial para que se anularan los indultos conferidos a los exmilitares y se aceleraran las causas judiciales contra los acusados de represión ilegal. Tres semanas después, el 24 de marzo de 2007, con ocasión del 31 aniversario del golpe militar de 1976, Kirchner pronunció un discurso en el predio del excentro de detención ilegal La Perla y se preguntó qué pasaba en la Cámara de Casación donde los juicios se encontraban parados ${ }^{4}$. Y expresó: "Yo le digo a la Justicia, y sé que el Consejo de la Magistratura me va a escuchar: ipor favor, basta! ¡Juicio y castigo!". Se refería de ese modo a la denuncia que 61 familiares y víctimas de la represión ilegal habían hecho contra el presidente de la Cámara de Casación, Alfredo Bisordi y otros tres camaristas por demoras en los procedimientos penales. Las declaracions del entonces presidente generaron un gran re-

\footnotetext{
3 Este equilibrio, del que la Corte es plenamente consciente en sus estrategias de legitimación (Fallon, 2005), es posible por la coherencia que existe en su estructura y procedimientos respecto de los mitos que la sostienen (Dowling y Pfeffer, 1975).

4 La Cámara Nacional de Casación Penal fue creada en el año 1992 como una instancia de unificación (“casación”) de las interpretaciones jurídicas de los tribunales penales inferiores (nacionales y federales). Como tal, se encuentra en la cúspide del sistema de aplicación de la ley penal y sus sentencias son revisadas, solamente, por la Corte Suprema de Justicia de la Nación.
} 
vuelo político y mediático -con contestación de Bisordi a Kirchner incluida- y motivó que la Corte Suprema emitiera un comunicado, que decía textualmente:

Con relación a la cuestión planteada, respecto de algunos jueces de la Cámara Nacional de Casación Penal, es preciso señalar que, sin perjuicio de que la conducta de los miembros de los tres poderes del Estado está sometida a controles republicanos, dicho control debe ser efectuado con mesura y equilibrio, utilizando los medios institucionalmente previstos, a fin de respetar la honorabilidad e independencia judicial.

Distintos miembros del Gobierno apoyaron al Presidente y criticaron a Bisordi en duros términos, pero fue Kirchner el que se ocupó de contestar directamente el comunicado de la Corte:

Asumo la responsabilidad de las cosas que digo. No puedo ser hipócrita... cuando digo que se siente una falta de justicia no estoy interfiriendo con un poder de la Nación. Cuando uno habla de la "corporación justicia" invade poderes que no se pueden invadir. No quiero invadir poderes, hemos trabajado duramente para que haya una Corte Suprema independiente... Cuando dicen que mis dichos son una desmesura, gracias a esa desmesura tenemos una nueva Corte, gracias a esa desmesura algunas cosas van cambiando en la Argentina... Creo que la desmesura es que hace cuatro años que estas causas están paradas; la desmesura es que los organismos de contralor que tienen que funcionar no hayan funcionado; la desmesura es que hay hermanos y hermanas que hace 31 años y más están esperando ver en el lugar que corresponde a aquellos que violaron todos los derechos humanos. ¿Y qué hay?

Este intercambio dio lugar a una amplia cobertura periodística, en el que tanto los habituales periodistas judiciales como los comentaristas políticos principales discutieron acerca de la independencia del Poder Judicial y el rol del presidente. En el plano institucional, el Consejo de la Magistratura dio curso a la investigación sobre el tribunal y se nombró instructor a un representante de los jueces, Luis Cabral. Mientras tanto, Bisordi pidió licencia por razones de salud. Sin embargo, a pesar de este revuelo inicial, luego de una semana la disputa se aquietó y el caso desapareció de los medios ${ }^{5}$.

Elegimos este caso en el marco de un estudio en el que relevamos todas las noticias publicadas por los 3 periódicos de alcance nacional de mayor influencia en la fijación de la agenda política argentina (Clarín, La Nación y Página 12), durante el primer semestre del año 2007. Durante el período que va de febrero a julio de 2007, esos periódicos publicaron 380 noticias con la Corte Suprema como protagonista. El caso Bisordi acumuló 46 notas periodísticas involucrando una variedad de enfoques, incluyendo noticias, notas

Pasada la efervescencia política y mediática, el caso seguiría su derrotero institucional por el Consejo de la Magistratura sin consecuencias para ninguno de los protagonistas. En junio de 2008, la presidenta Cristina Fernández de Kirchner aceptaría la renuncia presentada por Bisordi sin que se hubiera resuelto el procedimiento iniciado por el Consejo de la Magistratura. 
de opinión, reportajes y sólo excluyendo la información institucional. Es decir que, si nos atuviéramos a un estricto carácter cuantitativo, en lo que hace a la cobertura periodística de la Corte Suprema este caso fue el más relevante del primer semestre del año 2007. Pero sabemos bien que no es este el único criterio para la selección de un caso de estudio, sino que debe tenerse en cuenta su virtualidad explicativa, ello es, su capacidad para abrir nuevas vías de comprensión de una situación y para clarificar sus causas profundas. Se habla así de un "caso crítico" (Flybjerg, 2004), con importancia estratégica para el problema en general ya que permite abordar un aspecto del mismo poco conocido o desarrollado (Neiman y Quaranta, 2006). A diferencia de un modelo hipotético-deductivo, el método de caso se caracteriza por la apertura al propio desarrollo que el estudio va mostrando y encarna un planteamiento estrictamente problemático de la cuestión, pasible de generalización aunque en una forma distinta a la empleada por la lógica derivada de las ciencias duras.

En este sentido, el caso Bisordi nos presenta dos aristas de sumo interés. En primer lugar, por su notoriedad, el suceso trascendió el espacio que los periódicos generalmente dedican a las noticias sobre la Corte y llegó, durante varios días seguidos, a las primeras páginas de los periódicos. Ello hizo, además, que su tratamiento involucrara a los comentaristas políticos de los diarios, quienes muy raramente consideran a la Corte Suprema como un sujeto en sus opiniones. En segundo lugar, la dinámica confrontativa del caso y la posición que la Corte Suprema asumió al pedir "mesura y equilibrio”, implicaron que las distintas posiciones batallaran dialécticamente-generalmente, de modo más implícito que explícito-por imponer modelos distintos de legitimación judicial. Es decir, que en este caso, como veremos seguidamente, hay una discusión sobre el marco cognitivo que fija la posición institucional de la Corte y sobre el cual, consecuentemente, se medirá su legitimidad. Es bien sabido que los estudios sobre medios pueden referirse a los efectos formales de su acción -aspecto que describimos en el apartado anterior- o al contenido del mensaje. Habiendo recapitulado las distintas teorías que analizan científicamente la influencia de los medios en la conformación de lo dado por supuesto, nos concentraremos ahora en qué es lo que dicen los mensajes. A través de un análisis del discurso periodístico, buscaremos identificar los elementos centrales de las representaciones mediáticas. Para ello, dentro del pluralismo metodológico que caracteriza a este campo (Marradi, Archenti y Piovani, 2007; Petracci y Kornblit, 2007), utilizaremos un enfoque socio-hermenéutico que analice específicamente la retórica de los medios (Hart y Daughton, 2005). 


\subsection{Discurso y cultura política argentina}

Las representaciones sociales se articulan en un entramado cultural que, de modo subyacente, nutre las posiciones políticas que los actores expresan en la esfera pública ${ }^{6}$. Nuestro análisis intentará abordar el proceso de construcción de ese sustrato cultural, un proceso que, como señalamos más arriba, es eminentemente social y dialógico. Por lo tanto, los medios y las representaciones que producen van a cumplir una doble función en esa construcción: por un lado, van a ser instrumentos de ese proceso, generando ideas, imágenes y sentimientos que van penetrando la trama social y sedimentan en representaciones sociales; por otro lado, los medios se nutren de las representaciones existentes, las usan al describir y analizar la realidad y, en ese sentido, muestran algo de su existencia. En esta doble posición radica la importancia de las representaciones mediáticas: nos muestran al mismo tiempo algunos de los elementos presentes en el discurso de la sociedad civil, pero lo transforman en algo nuevo que, a su vez, genera cambios -en el corto o en el largo plazo- en ese discurso. Estas notas características van a hacer que el discurso mediático se presente como: a) parcial: los medios no muestran las representaciones sociales en su totalidad, sino que toman algunos elementos de ellas y los utilizan para procesar la realidad, muchas veces de modo contradictorio; b) difícil de descifrar: la lógica de los medios tiende a enmascarar la acción que realiza sobre la realidad, para que esta se presente como un reflejo de ella intuitivamente aceptable (Hart y Daughton, 2005); c) fluctuante: al ser terreno de luchas por el significado y por el hecho de ir tomando elementos parciales de las representaciones vigentes, el discurso periodístico no forma un bloque coherente sino que muestras facetas diferenciadas y, la mayor parte de las veces, en pugna.

La trama cultural de la que los medios forman parte y se nutren es la que brinda el campo de posibilidades en el que los discursos se van a articular. Fuera de ese sistema, carecerían de sentido y, por tanto, serían incomprensibles para los miembros de ese grupo social ya que es ese contexto el que les va a dar significado. Para Alexander, el significado que van a asumir los discursos depende de la interrelación de tres formas simbólicas: código, narrativa y género, bajo las cuales "los ciudadanos entienden las acciones de las autoridades políticas y de sus contrapartes” (1998: 3). Los códigos culturales se integran de forma binaria y definen los motivos, las relaciones sociales y las instituciones en términos de cualidades altamente simplificadas que separan lo bueno de lo malo, lo puro de lo impuro (Alexander, 2003). Estas estructuras son los elementos

6 Este entramado al que nos estamos refiriendo ha sido teorizado de distintas formas. Una de ellas es, en la ciencia política, la noción de cultura política (que, para Nohlen, es "la red de relaciones que se concreta en ideas y valores, en símbolos y normas compartidas por una sociedad, o sea una mentalidad que adquiere sentido en un contexto social y que guía y condiciona el pensar, el actuar y el sentir de los actores políticos" (2007: 7). Otra categoría que podríamos utilizar para entender la noción de entramado cultural es la de imaginarios sociales, tal como la utiliza Taylor (2006). 
con los que se elabora el discurso político, que se presenta así como una "batalla discursiva" en la que se define "quién va ser qué y por cuánto tiempo" (Alexander, 1998: 8). La imaginación colectiva, que es la que hace que los eventos sociales y políticos sean posibles, se construye sobre una narrativa o mito que le da sentido a ese relato. De ese modo, por ejemplo, la construcción social de la guerra requiere una narrativa que ponga la vida y civilización en peligro mortal” (Alexander, 1998: 9). El último elemento que configura el discurso es el género, que permite que el significado se forme. Los ciudadanos, continúa Alexander (1998: 12), "necesitan saber qué tipo de performance están viendo. Necesitan poner los personajes y la narrativa en un marco antes de saber -en el caso específico de la guerra- dónde el pensamiento apocalíptico se aplica”.

Estos códigos culturales de los que habla Alexander son compatibles con la noción de representación social a la que nos hemos estado refiriendo y, así, formarán parte de una cultura política de la que se van a nutrir los discursos que se produzcan en esa sociedad. El discurso concreto, por lo tanto, no surge de manera necesaria de esa trama cultural pero tampoco puede ser explicado fuera de ella. En el caso de sociedades con una larga vida institucional y raíces profundas en corrientes de pensamiento homologables, esos códigos tienen una fuerte estabilidad. En cambio, en el caso de sociedades más jóvenes o con un proceso de integración más reciente, como la argentina (Germani, 2003), se puede decir que ese discurso no se encuentra plenamente consolidado. Esto se expresa, por ejemplo, en los cambios de paradigmas del discurso que se van dando al compás de las crisis económicas, sociales y políticas que ha sufrido el país, incluyendo en ello la inestabilidad del sistema político. Resulta ajeno a los objetivos de este trabajo realizar un estudio pormenorizado del desarrollo histórico de los conceptos centrales de la cultura política argentina, por lo que simplemente abordaremos algunas líneas de tendencia que sentarán las bases para comprender mejor el discurso mediático del caso Bisordi. Entre ellas mencionaremos: a) la existencia de una fuerte cultura personalista, que se concreta en la centralidad casi monopólica de la figura presidencial y en una visión hegemónica de la política que tiende a negar al adversario (Botana y Mustapic, 1991; Palermo, 1985); b) la experiencia aguda de crisis recurrentes, que acortan las dimensiones temporales de los procesos políticos -cortoplacismo- (Quiroga, 2005) y debilitan las instancias mediadoras; y c) la falta de construcción institucional, producto de sucesivas interrupciones del orden, de la manipulación política y de una cierta preeminencia del contenido sobre la forma (Peruzzotti, 1999; Sebreli y Botana, 2006).

\subsection{Los discursos del caso Bisordi}

Los elementos mencionados van a encontrar su lugar en las voces de los distintos protagonistas del caso Bisordi. En este sentido, resulta importante recordar que el discurso de los medios no es autónomo, sino que 
se construye a partir de lo que dicen los actores políticos e institucionales. Por esta razón, cuando los medios reproducen estos discursos, las representaciones mediáticas se enmascaran y confunden con la realidad. Paradójicamente, los protagonistas de la vida política no se dirigen directamente al público -salvo en ocasiones muy especiales-, sino que su discurso está mediado por la prensa. Un primer objetivo de este análisis será, en la medida de lo posible, el de distinguir lo que es el discurso de los protagonistas de lo que son, propiamente, las representaciones mediáticas que se construyen sobre él ${ }^{7}$. En este sentido, el discurso del entonces presidente Kirchner retomó la tradición de un fuerte liderazgo a cargo del Ejecutivo, transmitiendo en sus intervenciones la imagen de sostener con firmeza las riendas del mando. Ese fuerte liderazgo se sostiene a través de la formulación de un dualismo beligerante ${ }^{8}$, en el que Kirchner se sitúa siempre del lado del pueblo. Así, en lo que hemos llamado "el caso Bisordi", frente a lo que llama la "corporación justicia”, el entonces presidente se coloca como voz de "los hermanos y hermanas" que hace 31 años que esperan justicia. Este dualismo se complementa con tres notas que Fidanza le atribuye a la "sociodicea" kirchnerista: la reinterpretación de las etapas de la historia argentina reciente, la asignación de responsabilidades y explicación del sufrimiento y la recuperación de la memoria y la identidad (Fidanza, 2004). Todas estas dimensiones son centrales en este conflicto, ya que solamente a través del "castigo a los culpables", el país recuperará la identidad y podrá iniciar una nueva etapa de "refundación”. Es el líder el que va a encarnar este proceso, luchando contra los poderes enquistados que impiden el cambio. El discurso presidencial va a reivindicar, entonces, la política de derechos humanos seguida por el Gobierno ya que ella representa los objetivos de memoria y justicia que Kirchner proclama. Y lo va hacer aun cuando ello genere algunas tensiones institucionales.

Estas tensiones, como vimos, son explicadas como consecuencia de presiones inerciales de las corporaciones, que no quieren resignar el poder acumulado. Frente a este discurso, la Corte va a asumir una posición distanciada y neutra, propia de la retórica judicial (Ferguson, 1990; Wetlaufer, 1990). En su comunicado, predomina la búsqueda de un equilibrio entre lo que considera una intervención necesaria pero en la que no quiere tomar partido sobre el fondo del asunto. Así, defiende la vía institucional para controlar a los magistrados, afirmando, al mismo tiempo, su accountability y negando que las presiones políticas sean una vía para ello. Su defensa, por tanto, evita el sesgo corporativo, a pesar de que su reivindicación de "la

Decimos "en la medida de lo posible" justamente porque la imbricación que se produce entre los actores políticos y los medios es tan estrecha, que la distinción puede realizarse a nivel analítico, pero no en un nivel real. Cf., en este sentido, Schudson, 2003.

8 Dualismo que "explica el origen y la naturaleza de las cosas por la acción de dos principios diversos y contradictorios" (Fidanza, 2004). Este dualismo, por otra parte, se conecta con el discurso del primer peronismo y la oposición entre pueblo y oligarquía (Sigal y Verón, 1982). 
honorabilidad e independencia judicial" pueden ser vistas de acuerdo con ese prisma. En cuanto al contexto en el que el mensaje es pronunciado y que condiciona su recepción, hay tres aspectos que destacar. En primer lugar, como recuerda el propio presidente, la "nueva" Corte es una obra del Gobierno. Para Kirchner -y por eso lo menciona en su discurso- la mera existencia de esta Corte habla de una preocupación institucional que funciona como salvaguardia de su discurso y lo exime de críticas radicales acerca de su celo por la institucionalidad democrática. Para la Corte Suprema, haber sido constituida por el Gobierno en funciones le da mayor margen de estabilidad y aleja la posibilidad de represalias. En segundo lugar, la Corte Suprema ha seguido una línea jurisprudencial que acompañó el programa del Gobierno en materia de Derechos Humanos (cf. Thury Cornejo, 2008) con lo cual su declaración no corre riesgos de ser entendida como una oposición de fondo a la postura presidencial. Por último, la Corte se fundó sobre la calidad académica y profesional de sus nuevos miembros, con lo cual el discurso distanciado que pronuncia adopta ese modo de expresión y aleja su postura de una posible asunción del rol de opositora.

Este posicionamiento relativo de los actores hace que entre el discurso de la Corte y el discurso presidencial no haya diferencias de fondo o sustanciales. Su enfrentamiento discursivo se produce de modo oblicuo, ya que la confrontación directa pareciera ser una opción de la que ninguno de los dos evalúa sacar mucho rédito. En ese sentido, Kirchner termina consiguiendo el efecto buscado -presión sobre la Casación y posicionamiento positivo frente a las organizaciones de Derechos Humanos-, neutralizando el efecto adverso del comunicado de la Corte. La Corte Suprema, por su parte, fija una posición institucional, sin enfrentarse a los objetivos del Gobierno. A partir de este empate técnico entre el Gobierno y la Corte Suprema, el resto de los actores políticos va a posicionarse en busca de sus objetivos. Algunos extremarían el discurso de los dos protagonistas centrales. Por ejemplo, Diana Conti, diputada oficialista y presidenta de la Comisión de Acusación del Consejo de la Magistratura, discutiría la presunta neutralidad de la Corte e intentaría aplicarle -implícitamente- el mote de "corporación judicial" mencionado por el presidente:

Esta Corte, que es independiente y renovada, usó una práctica de siempre, la misma práctica de la Corte menemista, que es un comunicado de prensa con frases que son clásicas dentro del Poder Judicial para pedir mesura y equilibrio" (La Nación, Página 12 y Clarín del 30-3-07).

El grueso del oficialismo, sin embargo, buscó contextualizar los dichos presidenciales, bajar el presunto nivel del conflicto con la Corte y concentrar su acción en el presidente de la Cámara de Casación, Alfredo Bisordi, quien había contestado airadamente el discurso inicial del Presidente ("no voy a ceder a ningún apriete, provenga de donde provenga", Clarín, 28-3-07). Las sociedades tradicionales de asociación judicial, como la Asociación de Magistrados y Funcionarios de la Justicia Nacional, cerraría filas con Bisordi, 
estimando que el presidente había incurrido en una "falta de consideración institucional hacia la alta investidura de los jueces" y que había cometido "una intolerable injerencia” en la actividad judicial (La Nación, 28-3-07). En cambio, otros actores, como el Colegio Público de Abogados de Capital Federal y distintos organismos de Derechos Humanos, se adhirieron a la denuncia contra los jueces de Casación, aunque evitaron referirse al pronunciamiento de la Corte (La Nación y Página 12, 28-3-07). En general, la mediatización de la discusión funciona como una ventana de oportunidad para que los distintos actores expresen sus opiniones políticas respecto de la visión de la figura presidencial y de la institucionalidad judicial.

Aparecen expresados así, en el cúmulo de discursos del caso Bisordi, varios de los conceptos pertenecientes al discurso de la sociedad civil argentina. Y lo hacen de modo dicotómico, como expresión de un proceso en el cual las representaciones sociales no se hallan aún consolidadas. En ese sentido, este caso constituye una batalla más en la lucha que libran los actores por imponer un determinado sentido al discurso público. El personalismo y la visión hegemónica que aparecían junto con la debilidad institucional como notas características de la cultura política argentina van a ser los núcleos a partir de los cuales se van a estructurar las díadas del discurso. En este caso, sin embargo, no van a aparecer bajo el anterior ropaje sino con la forma que le va a dar el encuadre de la cuestión en términos de legitimación política. La cuestión aquí va a ser quien puede encarnar-representar a ese pueblo. La visión personalista se va inclinar por la primera variante, la de la figura presidencial que corporiza al pueblo y que se opone a sus enemigos, adversarios a su vez de la memoria y de la justicia. La versión antinómica va a buscar horizontes que den estabilidad al sistema a través de lógicas de funcionamiento que se independicen -al menos parcialmente- de la del modus operandi político. Las instituciones y el Derecho serían instancias mediadoras, ralentizadoras de la esfera política. Esta dicotomía se expresa con radicalidad en estas declaraciones de Diana Conti: "Me gustaría saber qué ministros (de la Corte) hablan, yo tengo nombre y apellido, me llamo Diana Conti, soy diputada votada por el pueblo" (Página 12, 28-3-07). En la misma línea, agregaría unos días después, que "es muy útil para la República y la democracia que el presidente sea la voz de los que no tienen voz y denuncie lo que está mal, y lo diga y lo pelee" (La Nación, 30-3-07). Las instituciones son vistas, en este discurso, como algo que entorpece la voz del pueblo, como un lugar oculto y secreto donde se toman decisiones que le corresponden al pueblo $^{9}$. Las instituciones, en el discurso presidencial, son legítimas si expresan directa e inmediatamente la voz del pueblo. En este sentido, son vistas como algo abstracto (¿quiénes son los jueces que firman?) y opuestas a los liderazgos personales que son una representación concreta, una corporización del pueblo.

9 En palabras de Kirchner: "Señores: por hablar y decir lo que uno piensa, sin hipocresías, ¿ estamos poniendo en juego las instituciones de la República o estamos tratando de una vez de que las instituciones de la República se abran para que todos los argentinos vean qué pasa dentro de las instituciones?” (“Más críticas a La Nación”, La Nación, 29-3-07). 
Asimismo, en el decir presidencial, el discurso del Derecho, al igual que de las instituciones, es un freno que impide la dinámica creativa de la política democrática.

\section{4. ¿Cómo reflejó la prensa escrita este conflicto discursivo?}

Los medios intervienen de modos diversos en este conflicto. Por una parte, son el escenario donde la batalla dialéctica se produce y, así, los actores buscan protagonismo mediático para darle visibilidad a sus posturas. Por otra parte, y en este aspecto nos concentraremos en los párrafos que siguen, los medios moldean el sentido común a través del rol de comunicador de una realidad política a la que los ciudadanos no tienen acceso directo. En esa tarea, la prensa responde a una lógica propia de acuerdo con la cual seleccionan los contenidos y, una vez seleccionados, conforman los sucesos de una forma que les resulten atractivos -además de entendibles- a la audiencia. Estas dos operaciones están estrechamente relacionadas, ya que lo que no es traducible a la lógica mediática no podrá ser seleccionado para su publicación. La prensa escoge sólo una mínima parte de lo que sucede en el mundo y lo hace basándose en un criterio fundamental: la noticiabilidad o sea, la capacidad que tienen determinados sucesos para atraer la atención de los medios (Martini, 2000). ¿Qué notas definen esta noticiabilidad? En primer lugar, la noticia debe tener la forma de una historia, un suceso, y esa historia debe salir de lo rutinario, debe tener impacto (Patterson, 1984). Como expresan Martini y Luchessi, el valor de la noticia se mide "en términos de primicia y espectacularidad" y, por esa razón, "los acontecimientos que se hacen públicos tienen el carácter de imprevistos y de excepcionales” (Martini y Luchessi, 2004: 110).

Esa lógica de la excepcionalidad y el impacto genera, para resaltar estas características, un énfasis en el conflicto antes que el consenso. Esta característica adversativa de la cobertura periodística explica la enorme relevancia que los medios escritos argentinos le dieron al caso Bisordi. Un presidente que se dirige a un organismo de control de los jueces y le dice que proceda a castigar a los culpables de las demoras en juicios de lesa humanidad; uno de los jueces que contesta vehementemente el discurso presidencial; la Corte Suprema que interviene mediante un comunicado. Y todo ello referido a la política de Derechos Humanos, en una etapa en la que se discutía en la esfera pública acerca de la nulidad de los indultos otorgados por el ex presidente Menem. Todos los elementos del caso, pues, confluían en destacar los elementos de noticiabilidad y la prensa construyó un verdadero "espectáculo político" a su alrededor (Edelman, 1988). De este modo, lo que era un tema institucional -la relación del presidente con las instituciones judiciales y su independencia- se había transformado de pronto en un evento mediático. Porque es bien sabido que "las noticias tratan del evento, no de las condiciones subyacentes; de la persona, no del grupo; del conflicto, no del con- 
senso; del hecho 'que hace avanzar la historia', no del que la explica” (Gitlin, 1980: 28). Así, la lógica con la que se manejan los medios explica por qué el caso Bisordi tuvo tanta repercusión. En los apartados siguientes, iremos desgranando cómo los medios reflejaron este episodio y que visiones de la Corte y de las instituciones manejaron.

\subsubsection{El porqué del comunicado de la Corte Suprema}

La primera pregunta que deberíamos hacernos respecto del caso Bisordi es: ¿por qué interviene la Corte Suprema? En lo que hace a la dinámica mediática, esta pregunta puede responderse desde dos perspectivas. Desde un punto de vista de la dinámica política, el tribunal, al intervenir, responde a la mediatización de un suceso -el discurso de Kirchner y las reacciones políticas y judiciales posteriores- que llega a un punto en el que no puede -o se le hace muy costoso- ignorar. En efecto, la sociedad argentina estaba inmersa en un debate político sobre las consecuencias institucionales de las acciones presidenciales. Cuando éstas tocaron el nervio de la organización judicial, cuya jefatura efectiva la Corte Suprema estaba buscando liderar -frente al Consejo de la Magistratura-, al Tribunal Supremo le quedaron pocas opciones de acción ${ }^{10}$. Los medios, pues, tuvieron una gran influencia en la configuración del espacio simbólico en el que la Corte emitiría su comunicado. Ahora bien, y esto hace a la segunda perspectiva, ¿cómo reflejó la prensa esta dinámica? O, en otras palabras, ¿ cuáles fueron los motivos que los medios atribuyeron a la Corte para intervenir en el caso Bisordi? Nos concentraremos, pues, en las construcciones periodísticas sobre las acciones y motivos del tribunal.

Los medios consultados describen el proceso que llevó a la emisión del comunicado, presentando a la Corte como un actor racional que "evalúa”, "hace una composición de la situación” y tiene una visión prospectiva "sobre cómo ese mensaje es capaz de afectar la independencia judicial”" . La prensa construye una imagen de racionalidad que concuerda con el contenido del resto de las noticias, donde se dan amplias razones que justifican el accionar de la Corte Suprema y explican los condicionamientos a los que estaba sometida.

10 La ministra de la Corte, Carmen Argibay, expresaría en el marco de un debate académico que "no hubo intención de hacer una brecha. Es más, en este caso no estamos en contra del presidente" (Página 12, 30-3-07). Argibay pareciera expresar así la idea de que, de haber tenido mayores opciones reales, la Corte hubiera buscado no intervenir en este caso.

11 "El breve comunicado de la Corte fue difundido a última hora de la tarde de ayer, luego de que los jueces evaluaran que no podían permanecer en silencio frente a la dimensión de la polémica" (Silvana Boschi, Clarín, 28-3-07).

"Por eso los jueces supremos pusieron una señal de alerta sobre cómo ese mensaje es capaz de afectar la independencia judicial. La intención de la Corte, aclararon dos de sus miembros a Página 12, no es entrar en la discusión sobre la Cámara de Casación sino pedir respeto por la institucionalidad (....) Con ese mensaje, aclaró uno de los jueces, "no pretendemos defender a nadie en particular" (Irina Hauser, Página 12, 28-3-07). 
En este sentido, su accionar no es caprichoso sino que tiene una lógica implícita y ella es reproducible a posteriori. Pero esta no es la imagen general que la prensa trasmite de la Corte. Efectivamente, su racionalidad institucional se ve matizada por una personalización que le atribuye actitudes pasionales que morigeran su actitud de decisor racional. Así, la Corte se "preocupa”, “desconcierta” y “enoja”, mientras que los jueces se "sacan de quicio", se "fastidian". Por ejemplo:

Ayer, en los despachos de la Corte se percibía claramente la preocupación y el desconcierto que habían producido las palabras de Kirchner contra la Cámara de Casación (Adrián Ventura, La Nación, 28-3-07).

Lo que más enojó a la Corte Suprema no fue el discurso de Kirchner del 24 de marzo en sí mismo -según se empeñaron en aclarar- sino la escalada de voces que le siguieron, incluida la de Bisordi, que acusó por radio al Gobierno de buscar la “suma del poder público” (Irina Hauser, Página 12, 29-3-07).

La espiral de declaraciones de funcionarios políticos en los medios y el ping-pong que tuvo a Bisordi como protagonista sacó de quicio a varios jueces de la Corte (Irina Hauser, Página 12, 28-3-07).

Esta personalización que realiza la prensa tiende a psicologizar el comportamiento institucional y acerca, de algún modo, la institución al lector a través de un proceso de identificación (Burke, 1969). La Corte, tenderíamos a pensar, tiene actitudes y sentimientos parecidos a los nuestros; por lo tanto, podemos comprenderlos e identificarnos con ella. Esta operación "humanizadora" de la prensa, sin embargo, se contradice con los rasgos que la retórica judicial tiende a realzar y que se encuentran mejor representados por esa imagen de racionalidad institucional (Kahn, 1999). Esta "grieta" en la imagen institucional del Poder Judicial se complementa con la operación a través de la cual los cronistas se presentan como nuestros guías en la dinámica oculta de los despachos de Tribunales. El autor de la noticia nos va a mostrar el lado oculto de las decisiones de la Corte y él, como el único conocedor de sus secretos, va a ser el artífice que articula un relato donde se mezclan razones, pasiones y emociones. El periodista es el que nos va a descubrir y explicar el backstage, citando fuentes de información anónimas a las que solo él tiene acceso y que se mantienen protegidas por el secreto periodístico. Son comunes entonces los trascendidos ("en un despacho se oyó decir...”, La Nación, 28-3-07) y las fuentes informales ("La intención de la Corte, aclararon dos de sus miembros a Página 12...", 28-3-07).

Mediante la operatoria descripta, las noticias desmitifican las decisiones de la Corte y ofrecen un contrapunto al distanciado y neutro lenguaje judicial del comunicado. Ello es, la prensa realiza una contextualización del acto simbólico con el que la Corte intervino de modo breve y conciso y es allí en donde aparecen -bien o mal, verdaderas o falsas- las explicaciones que el tribunal no provee. De este modo, la cobertura periodística provoca un quiebre en el discurso oficial de la Corte Suprema. Como se ha ocupado de 
destacar la doctrina americana, el discurso judicial, formal y objetivo, tiende a difuminar el elemento humano en las decisiones, cumpliendo así la función política y simbólica de demostrar que no es un gobierno de hombres al que estamos sujetos, sino un "gobierno de leyes" (Chemerinsky, 2002, 2006). La dinámica periodística va en el sentido contrario: mostrar que hay protagonistas humanos que toman decisiones y que ellas no necesariamente son siempre racionales, sino que hay elementos pasionales que entran en juego. Esta tendencia de la noticiabilidad periodística choca estructuralmente con los principios de la retórica judicial pero, en este caso, ese quiebre no produce efectos contradictorios sobre la acción discursiva ya que lo que la prensa destaca al indagar el interior de la Corte es el consenso con que contó la decisión. La acción de la prensa legitima, de algún modo, la decisión del Tribunal al mostrar el consenso real existente, pero en ese mismo acto muestra el potencial deslegitimante que esa lógica de actuación mediática tiene.

\subsection{2. ¿Qué rol cumple la Corte Suprema en el conflicto?}

El hecho de que la Corte sea mostrada como un ente concreto, dotado de voluntad, inteligencia y pasiones, con una dinámica interior, es el presupuesto necesario para narrar una historia, que es el objetivo que va a buscar el periodista. Esta historia, como vimos, va a encarnar un conflicto y formalmente va a asumir un género discursivo. Como señala Todorov, los "autores escriben en función del sistema genérico existente (...) y los lectores leen en función del sistema genérico que ellos conocen mediante la crítica, la escuela, el sistema de difusión del libro o simplemente mediante el decir de la gente; sin embargo, no es necesario que ellos estén conscientes de ese sistema” (Todorov, 1996: 53). En este sentido, la elección del género que estructura la noticia es un poderoso instrumento retórico que va a responder a los objetivos del autor (Devitt, 2000) y que va a codificar la información que el lector recibe, generalmente de un modo inconsciente. El género al que van a responder las noticias del caso Bisordi, se compone de elementos dramáticos, épicos y realistas, que fluctúan dependiendo de la composición que hacen los distintos medios de prensa. El género "drama" tiende a generar atención - particularmente, la tragedia- y presupone la idea de una situación adversativa, conectándose así con las nociones de espectacularidad de la noticia y de conflicto, componentes tradicionales de la noticiabilidad (Martini, 2000). Algunos de los titulares de noticias y comentarios nos ilustran acerca de ello:

“La República está en serio peligro” (editorial La Nación, 28-3-07).

“El presidente pone al país al borde de un conflicto de poderes” (opinión de Morales Solá, La Nación, 28-3-07).

“Poder Ejecutivo vs. Jueces” (opinión de Eduardo Padilla, Clarín, 30-3-07).

"La larga sombra del Unicato" (opinión de Mariano Grondona, La Nación, 1-4-07). 
La configuración de esta situación dramática va a llevar -aunque sea de modo implícito- a teñir la actuación de la Corte de un tono que recuerda lo épico. En ese sentido, no todos los discursos mediáticos van a ser semejantes, sino que esta característica va a verse desarrollada en el tratamiento que los diarios $\mathrm{La} \mathrm{Na-}$ ción y Clarín dieron al tema. En el discurso del primer periódico citado es Kirchner el que toma "el liderazgo personal de la crispación frente a los jueces”, mientras que en Clarín se afirma que es la Corte la que va poner "las cosas en el lugar donde deben estar" (opinión de Ricardo Roa, Clarín, 28-3-2007). O sea que, en términos del discurso, estos medios van a crear una necesidad -imperiosa- que la Corte va-de algún modoa satisfacer. Estos elementos dramáticos y épicos elevan la importancia simbólica de los sucesos que relatan (Alexander, 1998) y contribuyen así a dotar de trascendencia al conflicto que se describe y analiza ${ }^{12}$. En la trama de las noticias, sin embargo, estos elementos van a estar balanceados por la irrupción de elementos realistas, que son los más propios del discurso periodístico en la medida que refleja la dinámica política como un juego de intereses (Patterson, 1994). El realismo, entonces, implica una visión estratégica y predomina en la ida y vuelta de opiniones que publican los periódicos así como en la enumeración de los elementos que tienen en cuenta los actores para decidir. Para este género, lo realmente valioso son los aspectos instrumentales de la acción y, así, los "altos intereses de la República" son reemplazados por las "presiones de los jueces de todo el país" o la "necesidad de llevar seguridad al Poder Judicial”. Este realismo, para Alexander, es el "género más deflacionario de todos" (1988: 13) y su uso periodístico tiende a quitarle a los sucesos los elementos valorativos que están en juego. En el caso que estamos analizando, el realismo se combina con los elementos dramáticos y épicos y ello aleja a la Corte de una lógica de actuación puramente instrumental, pero esta dimensión nunca desaparece por completo. Más bien, los tres elementos que componen el género de estas noticias culminan en un producto que es, al mismo tiempo, balanceado y pasible de múltiples lecturas.

En este drama que protagoniza la Corte, realista y épico a la vez, ella va a tener un papel principal: va a ser el árbitro que está por encima de la disputa política. Este es un rol que la Corte se auto-asigna a través de la emisión de un comunicado escueto y formal. Este doble enfoque va a generar, al nivel del discurso, muchas dificultades interpretativas ya que los mensajes contenidos son contradictorios. Al igual que en el caso de la tensión entre racionalidad institucional y humanización personalizadora que analizamos en el punto anterior, existe una contradicción entre la lógica periodística que dramatiza el conflicto y la posición mediadora que la Corte intenta asumir. De hecho, la referencia a la épica que hicimos anteriormente saca a la Corte de su lugar neutral y la enfrenta, aunque más no sea discursivamente, al presidente y al Gobierno. Pero

12 No es casual, en este sentido, que en un periódico más inclinado a escuchar favorablemente las voces gubernamentales, se califique a todo este episodio bajo el signo de la farsa ("Salsa Criolla”, opinión de Horacio Verbitsky, Página 12, 1-4-07). 
este hecho se configura como una construcción que se deriva más de la narración mediática que de la propia situación real. La Corte Suprema, con actitud cautelosa, fijó su posición en el conflicto. El presidente Kirchner contestó los dichos de la Corte y los puso en duda cuando jugó con las palabras y dijo que gracias a su desmesura, el tribunal podía existir y haber dicho lo que dijo. La Corte no le respondió al presidente, ni oficialmente ni a través de sus ministros en forma individual y ello reforzó su auto-colocación como árbitro y no como parte de la disputa. De este modo, la Corte no le dio a la prensa los suficientes elementos como para que la convirtiera en antagonista del presidente ${ }^{13}$. De hecho, la misma prensa reconoció -y felicitó- esa situación, en la medida en que contribuía a la construcción de su discurso "institucional"14.

Es necesario resaltar, en esta instancia, que existe una evidente tensión entre el rol que la Corte quiso asumir y las necesidades periodísticas de construir un antagonismo ${ }^{15}$. La prensa usó las posibilidades del género, construyó un marco que necesitaba contrincantes y usó, en la medida en que la realidad lo permitía, a la Corte para ese fin. Pero en realidad, los dos grandes protagonistas de la contienda fueron el presidente y la prensa ${ }^{16}$. El primero ocupó el centro del escenario y la prensa se constituyó, de modo generalmente implícito, como su antagonista principal ${ }^{17}$. Para ello, creó, a través de la construcción periodística de los dichos del presidente Kirchner, una situación en la que se generó un vacío discursivo que había que llenar ${ }^{18}$. La lógica antagónica requería un contrincante de peso para el Gobierno y la Corte, con su comunicado, vino a llenar ese lugar. Pero el lugar asumido por la Corte y los mensajes que pronunció no fue suficiente para sostener el rol que la prensa le había otorgado. En consecuencia, la prensa asumió ese rol y utilizó su propia voz a través de sus columnas de opinión. En este aspecto, entendemos que fue clave la estrategia comunicativa de la Corte Suprema que habló de modo institucional y neutro y luego calló, dejando

13 Sí lo hizo, por el contrario, el juez Bisordi, pero no tenía la estatura necesaria para ser un interlocutor verdadero de Kirchner (ni el presidente lo reconoció como tal - $\nu$. gr: no lo nombró por su nombre en los discursos- ni la prensa le dio consistentemente tal rango).

14 "Por principio, un cuerpo como el hoy presidido por Ricardo Lorenzetti debe preservar hasta el último instante su natural condición mediadora entre los actores del país. El solo hecho de que haya considerado dejar sentada una primera posición con el prurito con que lo hizo ante la lamentable situación producida, merece ser rescatado como una muy valiosa contribución al interés general de la República” ("Mesura y concordia”, editorial La Nación, 1-4-07).

15 Recordamos que la construcción de este antagonismo se da, principalmente, en La Nación y, en menor medida, en Clarín.

16 Limitamos esta afirmación al caso de La Nación y Clarín. Como veremos en el apartado siguiente al analizar la línea editorial de los periódicos, la postura de Página 12 fue distinta a la seguida por los diarios de mayor tirada.

17 En el caso de La Nación, la confrontación con el presidente ya había sido formulada explícitamente por Kirchner y planteada por el diario. El jueves 29 de marzo de 2007, La Nación publica un apartado bajo el título "Más críticas a La Nación" donde recoge los dichos del presidente en referencia a la trayectoria del diario.

18 El mismo día en el que, por la tarde, la Corte Suprema emitió su comunicado (27-3-07), La Nación publicó en primera plana un reportaje a Bisordi bajo el título: "Vamos hacia la suma del poder público". 
que la dinámica de los medios siguiera su curso. Su silencio posterior explica así la enorme proporción de editoriales y comentarios políticos firmados que el caso generó, haciendo pervivir el conflicto a pesar de la relativa escasez de nuevos hechos que reportar. La prensa carecía así de respuestas institucionales a su accionar y asumía el conflicto en sus propios términos.

\section{Conclusiones}

El estudio del caso Bisordi demuestra que los medios de prensa desempeñan un rol fundamental en la construcción de la realidad y en la conformación de la dinámica política. Como dijimos en la primera parte, la legitimidad es una creencia y, como tal, forma parte de la cultura. Los medios son actores culturales, es decir, son productores de significados, símbolos y mensajes. En este sentido, su influencia se da por la formación de una red de significados, una trama cultural, que el público -y los actores políticosusan en su actividad cotidiana. Los significados que la prensa transmite, subliminalmente en su "reflejo" de la realidad y más explícitamente en sus opiniones directas, contribuyen a formar la base sobre la cual se construyen los marcos de entendimiento de la política y se edifican las acciones posteriores (Schudson, 2003). La actividad de los medios tiene entonces una doble dimensión temporal: en el mediano-largo plazo, las imágenes que transmite contribuyen a formar representaciones sociales estables y duraderas en la audiencia; en el corto plazo, la prensa funciona como amplificador de las noticias que provienen del ámbito político y de sus repercusiones, y construye el escenario para el debate público. Ahora bien, esa difusión y amplificación no se da de un modo neutro sino que reflejan una lógica específica, que transforma los sucesos de la realidad en sucesos mediáticos. Al hacerlo, se produce una mutación que muchas veces hace que el resultado de la actividad de los medios provoque un quiebre en el sentido original del mensaje transmitido. Por ello, la relación entre la Corte Suprema y los medios es necesariamente compleja, en un sentido que la aleja de esquemas mecanicistas y simplificados como el que presupone una mera política comunicacional de difusión.

En este sentido, el caso Bisordi expresa muchas de las quiebras que se producen entre la lógica judicial, que obedece a un sistema que estructura un modelo de toma de decisiones basadas en el Derecho, y la lógica periodística, que privilegia el evento sobre las condiciones estructurales, el conflicto sobre el consenso, lo excepcional sobre lo cotidiano. Una de las preguntas que tratamos de responder en este trabajo es: ¿qué es lo que atrajo a los medios del caso Bisordi y lo transformó en un suceso de primera plana y objeto de comentarios políticos? La respuesta está en que fue un suceso que la prensa pudo traducir fácilmente a los términos de la noticiabilidad y darle la categoría de suceso mediático. En esas condiciones, pues, la Corte 
Suprema llegó a las portadas periodísticas. A la luz del desarrollo que hemos realizado, esta respuesta podría aparecer como una verdad de Perogrullo y sin demasiada virtualidad para generar conocimiento ulterior aplicable a las políticas comunicativas del Alto Tribunal. Sí lo tiene, sin embargo, si la analizamos desde lo que el caso no muestra, ello es, ¿en qué condiciones puede (o debe) la Corte Suprema atraer la atención de los medios para lograr una mejor difusión de sus acciones? ¿2Puede abstraerse de la lógica periodística que hemos descrito? ¿Puede salir su mensaje indemne del conflicto de lógicas que se plantea? La respuesta a esta pregunta no podría ser agotada en unas breves páginas, pero el caso Bisordi nos permite al menos avizorar la profundidad y complejidad del desafío que la política comunicacional de la Corte Suprema genera. Entre las dimensiones que han salido a la luz de las relaciones entre prensa escrita y Corte Suprema, nos interesa destacar los siguientes puntos:

1) La caracterización que los medios hacen de la Corte Suprema como actor público es matizada, ya que destacan su racionalidad pero también incluyen elementos emocionales. Esto tiende a humanizarla y acercarla a la audiencia, en la medida en que ésta se pueda identificar con esas reacciones. En este caso se trata de una discusión institucional, frente a un presidente temperamental, y las reacciones que la prensa le adjudica a la Corte son congruentes con la situación y favorecen la identificación referida. La Corte se nos muestra como celosa de las inmunidades judiciales y dispuesta a defenderlas. Sin embargo, existe un potencial conflicto entre la lógica racional que estructura el lugar institucional de la Corte, el modo en que se expresa y las funciones que cumple, y la lógica mediática que está detrás de la "humanización" del Tribunal, con su focalización en los elementos emocionales. Otro tanto sucede con la tendencia de la prensa a intentar mostrar la actividad interna de la Corte y transcribir declaraciones anónimas. Así como en la humanización del Tribunal había una congruencia entre los resultados de las emociones mostradas y el proceso racional seguido, aquí lo que la prensa desvela del mundo interior de la Corte es una cohesión entre los ministros del Tribunal. El resultado, debido a esta concordancia, acrecienta la fuerza y legitimidad de la decisión. Pero lo que deberíamos tener en cuenta es que esa coincidencia es coyuntural, ya que estructuralmente las lógicas actuantes divergen. Justamente, la razón por la que los Tribunales Supremos tienden a neutralizar el conflicto, ya sea a través de la necesaria unanimidad de sus decisiones - $v$. gr: Tribunal Constitucional francés- o de la formalización del disenso - v. gr: Corte Suprema de los EE.UU. (cf. Kahn, 1999)es la necesidad de que la decisión judicial sea vista como la única solución posible al problema, lo que refuerza su condición de "dado por supuesto". En estos términos, desde un punto de vista de la legitimidad cognitiva, la humanización y la revelación de sus negociaciones internas a los que lleva la lógica periodística tienden a deslegitimar las decisiones judiciales. 
2) En este caso, la Corte Suprema intervino en la esfera pública ante una situación en la que las presiones del ambiente lo tornaron prácticamente inevitable. Eligió hacerlo de un modo prudente y acotado, a través de un comunicado institucional. La elección de esta vía de acción contribuyó a delinear el rol que la prensa le atribuyó en el conflicto, en gran medida porque la índole del comunicado fue congruente con el rol de árbitro y moderador en la contienda. Su lenguaje neutro y desapasionado, despegado de las contingencias menores del caso, y su defensa de la institucionalidad fueron el género formal que la Corte eligió para representar su papel. La prensa no logró deconstruir estas expresiones del Tribunal y transformarlas en componentes del género periodístico en el que estructuró el caso. En otras palabras, la Corte respondió a su lógica tradicional de actuación -lo que le endilgaba la diputada Conti al emparentar a la actual Corte con la Corte menemista- y de ese modo sus dichos, no pudieron ser utilizados de acuerdo con la lógica mediática. En este caso, el Alto Tribunal, de haber sido otra su actuación, estaba destinado a ser el contendiente del Gobierno y, sin embargo, no solamente salió airoso del trance sino que su imagen institucional se vio fortalecida. Esta característica realza el enorme valor que una estrategia comunicacional tiene con relación al poder de los medios. Basta comparar, en este sentido, los resultados de una política institucional como la seguida por la Corte frente al enfrentamiento personal al que se expuso el juez Bisordi. La prudencia institucional empleada refuerza el rol moderador de la Corte y la coloca por fuera del conflicto político, acrecentando su autoridad judicial -lo cual hace, probablemente, que sea habitualmente tan poco "noticiable".

3) En el tratamiento de las noticias que dan cuenta del comunicado de la Corte Suprema, los tres periódicos analizados utilizan una lógica similar de noticiabilidad e impacto. Sin embargo, la cobertura general de cada medio difiere en cómo construye el conflicto -para La Nación es un tema de instituciones, para Clarín es una pelea política en año electoral y para Página 12 es un asunto de derechos humanos- y en cómo repercute sobre la posición general del periódico respecto del tema de fondo. Este punto es el que, probablemente, más nos dice sobre la legitimidad de la Corte Suprema ya que lo que la discusión revela es que no hay respecto de ella un marco cognitivo uniforme. La discusión implícita se da acerca de la dicotomía entre instituciones y democracia y ella involucra el rol de la Corte como institución cuya legitimidad provendrá de responder directamente al factor democrático o, indirectamente, a través de su carácter contramayoritario. Citemos, por ejemplo, el artículo de opinión con el que Irina Hauser cierra este caso en Página 12:

El Presidente Néstor Kirchner viene haciendo con la Cámara de Casación lo mismo que hizo en su momento con la Corte Suprema de la mayoría automática: recoger un reclamo social y ponerlo a la cabeza de su agenda (...) Podríamos pasar horas y días discutiendo si Kirchner cometió una intromisión en la Justicia al pedir celeridad 
en las causas de derechos humanos y cuestionar a Casación. No tiene mucho sentido enredarse en ese debate al que la propia corporación judicial, donde subsisten las ideas de la derecha más pura, se encargó de dar cuerda (“Independencias", 3-4-07).

Mientras para La Nación lo que está en juego es "la salud de la República”, para Página 12 es un tema en el que lo importante es que Kirchner se pone al frente de un reclamo social -principio democrático directoy por ello no tiene mucho sentido gastar tiempo en hablar de la regularidad institucional de su pedido -tema que, por otra parte, es descalificado al emparentarlo con la "derecha más pura”-. Más allá del lugar ideológico en el que cada uno se sitúe en ese debate, es claro que esta discusión periodística revela la inexistencia de una base común sobre la cual pudiera ser medida la actuación de la Corte Suprema. O sea, el marco cognitivo respecto del cual habría que medir la actuación del Tribunal está lejos de ser unívoco. No hay consenso sobre el papel que ella debe cumplir en un sistema democrático como el argentino, porque no hay un acuerdo previo sobre el rol que las instituciones en general deben cumplir en él.

En suma, pues, este caso ilustra varias dimensiones de la forma en que la prensa escrita argentina representa a la Corte Suprema de Justicia y las dimensiones de legitimidad que así se ponen en juego. Los hallazgos del caso Bisordi requieren ser profundizados y confrontados con otras experiencias, pero dejan apuntadas interesantes líneas que tener en cuenta en el diseño de una política comunicacional que dé cuenta de la complejidad de la relación con los medios de comunicación. En primer lugar, la prensa se configura como un aliado peligroso, que se rige por una lógica propia, difícil de ser manejada externamente. En este sentido, que la Corte Suprema de EE.UU. elija tener un trato sumamente restringido con los medios (Thury Cornejo, 2009a) no aparece como una opción caprichosa sino como un intento de preservar la lógica propia de actuación judicial y no ser colonizada por la periodística. En segundo lugar, si la relación con los medios se presenta como riesgosa, sería recomendable que la Corte Suprema diseñe una política que, sin excluir a los medios, busque llegar al público general a través de algunos canales de comunicación directos o a través de la construcción de mensajes que eviten la tergiversación de la lógica judicial. Finalmente, habiendo visto la falta de consenso sobre el rol efectivo de la Corte Suprema en el esquema institucional argentino, sería deseable una mayor auto-conciencia del Tribunal sobre el papel que desempeña y que se tradujera en una fundamentación más explícita de las razones jurídico-institucionales que lo fundan. Mientras en el caso de EE. UU. ese ejercicio de auto-reflexión es habitual (Perry, 1999), en la jurisprudencia argentina no aparece como un nudo problemático. Este movimiento no solucionará los desacuerdos más profundos, pero significará una posición más activa de la Corte Suprema en la discusión de su identidad y en su comunicación a la ciudadanía. 


\section{Referencias bibliográficas}

ADC/Asociación por los Derechos Civiles (2008): La Corte y los derechos 2005/2007. Cómo impactan en la vida de los ciudadanos las decisiones del máximo tribunal, Buenos Aires: Siglo XXI editores.

Alexander, J. C. (1998): "Bush, Hussein and the Cultural Preparation for War: Toward a More Symbolic Theory of Political Legitimation”, Epoche: Journal for the Study of Religions, vol. 2, n. 1, pp. 1-12.

- (2006): The Civil Sphere, Oxford: Oxford University Press.

Baczko, B. (1999): Los imaginarios sociales, Buenos Aires: Nueva Visión.

Bellah, R. N. (1967): “Civil Religion in America”, Daedalus Vol. 96, n. 1, pp. 1-21.

Berkson, L. (1978): The Supreme Court and its Publics, Lexington, Massachussets: Lexington Books.

Botana, N. R. y Mustapic, A. M. (1991): “La reforma constitucional frente al régimen político argentino”, en Dieter Nohlen y Liliana de Riz (compiladores), Reforma Institucional y Cambio Político, Buenos Aires: Legasa.

Burke, K. (1969). A Rhetoric of Motives. Berkeley: University of California Press.

Carrió, A. (1996): La Corte Suprema y su independencia, Buenos Aires: Abeledo Perrot.

Casey, G. (1974): “The Supreme Court and Myth: An Empirical Investigation”, Law and Society Review, vol. 8, n. 3, pp. 385-420.

Chemerinsky, Erwin (2002): “The Rhetoric of Constitutional Law”, Michigan Law Review vol. 100, pp. 2008-2035.

Chemerinsky, Erwin (2006): "Seeing the Emperor’s Clothes: Recognizing the Reality of Constitutional Decision Making", Boston University Law Review, vol. 86, pp. 1069-1081.

Couldry, N. (2004): “Theorising Media as Practice”, Social Semiotics, vol. 14, n. 2.

Davis, R. (1994): Decisions and Images. The Supreme Court and the Press, Englewood Cliffs, NJ: Prentice Hall.

De Páramo Argüelles, R. (1990): “Obediencia al derecho: revisión de una polémica”, Isegoría: Revista de filosofía moral y política, n. 2, pp. 153-161

Devitt, A. J. (2000): “Integrating Rhetorical and Literary Theories of Genre”, College English, 62: 6, pp. 696-718.

Dowling, J. B. y Pfeffer, J. (1975): “Organizational Legitimation”, Pacific Sociological Review, vol. 18, n. 1, pp. 122-136.

Edelman, M. (1967): The Symbolic Uses of Politics, Urbana/Chicago: University of Illinois Press.

- (1988): Constructing the Political Spectacle, Chicago y London: The University of Chicago Press.

Engstrom, R. L. y Giles, M. W. (1972): “Expectations and Images: A Note on Diffuse Support for Legal Institutions”, Law and Society Review, vol. 6, n. 4, pp. 631-636.

Ferguson, Robert (1990): “The Judicial Opinion as Literary Genre”, Yale Journal of Law y Humanities, vol. 2, n. 1. 
Fidanza, E. (2004): “La sociodicea de Néstor Kirchner”, Revista Criterio, año 77, n. 2292.

Flybjerg, B. (2004): "Cinco malentendidos acerca de la investigación mediante los estudios de casos", Revista Española de Investigaciones Sociológicas, n. 106.

Gerbner, G. (1998): “Cultivation Analysis: An Overview”, Mass Communication y Society, vol. 1, n. 3, pp. $175-194$.

Germani, G. (2003): Autoritarismo, Fascismo y Populismo nacional, Buenos Aires: Temas Grupo Editorial.

Gitlin, T. (1980): The Whole World Is Watching, Berkeley: University of California Press.

Graber, D. (2002): Mass Media and American Politics (6 ${ }^{\text {th }}$ ed.), Washington, DC: CQ Press.

Grafstein, R. (1981): “The Legitimacy of Political Institutions”, Polity, v 14, n. 1, pp. 51-69.

Hamilton, A.; Madison, J. y Jay, J. (1994): El Federalista, México: Fondo de Cultura Económica.

Hart, R. P. y Daughton, S. (2005): Modern Rhetorical Criticism (3ra. ed.), Boston, MA: Pearson.

Kahn, P. W. (1999): The Cultural Analysis of Law. Reconstructing Legal Scholarship, Chicago: The University of Chicago Press.

Kapiszewski, D. (2006): “La Corte Suprema y la Política Constitucional en la Argentina Post-Menem”, Revista Jurídica de la Universidad de Palermo, año 7, n. 1.

Lerner, M. (1937): “Constitution and Court as Symbols”, The Yale Law Journal, vol. 46, n. 8, pp. 1290-1319.

Litvachky, P. y Zayat, D. (2007): "Procesos de cambio en la justicia argentina: hacia un nuevo modelo de Corte Suprema y el futuro del Consejo de la Magistratura”, en Derechos Humanos en Argentina. Informe 2007, CELS (ed.), Buenos Aires: Siglo XXI.

Lorenzetti, R. L. (2007): Políticas de Estado para el Poder Judicial, [discurso pronunciado en la Segunda Conferencia Nacional de Jueces], Salta, Argentina.

Marradi, A., Archenti, N. y Piovani, J. I. (2007): Metodología de las Ciencias Sociales, Buenos Aires: Emecé.

Martini, S. y Luchessi, L. (2004): Los que hacen la noticia. Periodismo, información y poder, Buenos Aires: Biblos.

Martini, S. (2000): Periodismo, noticia y noticiabilidad, Buenos Aires: Norma Editorial.

Melucci, A. (2001): Vivencia y Convivencia. Teoría social para una era de la información, Madrid: Trotta.

Miller, J. (2000): “Control judicial de constitucionalidad y estabilidad constitucional: Sociología del modelo estadounidense y su colapso en la Argentina”, Revista Argentina de Teoría Jurídica, vol. 1, n. 2.

Moscovici, S. y Markova, I. (1998): “Presenting Social Representations: A Conversation”, Culture y Psychology, n. 4, pp. 371-410.

Murray, M. (2002): “Connecting Narrative and Social Representation Theory in Health Research”, Social Science Information, vol. 41, n. 4, pp. 653-673. 
Neiman, G. y Quaranta, G. (2006): “Los estudios de caso en la investigación sociológica”, en Irene Vasilachis de Gialdino (coord.), Estrategias de investigación cualitativa, Barcelona: Gedisa.

Nohlen, D. (2007): Instituciones y cultura política, Ciudad de México: Instituto Electoral del Estado de México.

Palermo, V. (1985): “Cultura política, conflicto y democracia”, en Ariel H. Colombo y Vicente Palermo: Participación política y pluralismo en la Argentina contemporánea, Buenos Aires: Centro Editor de América Latina.

Patterson, T. E. (1994): Out of Order, New York: Vintage Books.

Perry, B. A. (1999): The Priestly Tribe. The Supreme Court's Image in the American Mind, Wesport, CT: Praeger.

Petracci, M. y Kornblit, A. L. (2007): “Representaciones sociales: una teoría metodológicamente pluralista”, en Ana Lía Kornblit (coord.): Metodologías cualitativas en ciencias sociales. Modelos y procedimientos de análisis, Buenos Aires: Biblos.

Pharr, S. J. y Putnam, R. (ed.) (2000): Disaffected democracies: what's troubling the trilateral countries?, Princeton, N. J.: Princeton University Press.

Phillips, N., Lawrence, T.B. y Hardy, C. (2004): “Discourse and Institutions”, The Academy of Management Review, vol. 29, n. 4, pp. 635-652.

PNUD -Programa de las Naciones Unidas para el Desarrollo- (2005): Informe de Desarrollo Humano 205. Argentina después de la crisis. Un tiempo de oportunidades, Buenos Aires: PNUD.

Quiroga, H. (2005): La Argentina en emergencia permanente, Buenos Aires: Edhasa.

Raudsepp, M. (2005): “Why Is It So Difficult to Understand the Theory of Social Representations?”, Culture y Psychology, vol. 11, pp. 455-468.

Schudson, M. (2003): The Sociology of News, New York-London: Norton.

Sebreli, J. J. y Botana, N. R. (2006): “¿Sociedad sin instituciones”?, Revista Criterio, año 79, n. 2319 (septiembre).

Sigal, S. y Verón, E. (1982): "Perón: discurso político e ideología", en Alain Rouquié (comp.): Argentina, hoy, Buenos Aires: Siglo Veintiuno Editores.

Smulovitz, C. (1995): "Constitución y Poder Judicial en la nueva democracia argentina. La experiencia de las instituciones”, en Carlos Acuña (ed.): La nueva matriz política argentina, Buenos Aires: Nueva Visión.

Street, J. (2004): “Celebrity Politicians: Popular Culture and Political Representation”, British Journal of Politics y International Relations, vol. 6, pp. 435-452.

Suchman, M. (1995): “Managing Legitimacy: Strategic and Institutional Approaches”, The Academy of Management Review, vol. 20, n. 3, pp. 571-610.

Taylor, Ch. (2006): Imaginarios sociales modernos, Barcelona: Paidós. 
Thompson, John B. (2005): “The New Visibility”, Theory, Culture y Society, vol. 22, n. 6, pp. 31-51.

Thury Cornejo, V. (2008): “La 'nueva' Corte Suprema y sus estrategias de legitimación”, El Derecho, Suplemento de Derecho Constitucional, miércoles 20 de febrero.

- (2009a): "La legitimidad de los tribunales supremos y sus estrategias comunicativas. El caso de de la Corte Suprema de EE.UU.”, Estudios Constitucionales, año 7, n. 2, pp. 243-275.

- (2009b): "Could authenticity fill the gap", Revista Realidad, n. 6.

Todorov, T. (1996): Los géneros del discurso, Caracas: Monte Ávila Editores Latinoamericana.

Tyler, T. R. (1997): “Public Mistrust of the Law: A Political Perspective”, University of Cincinatti Law Review, vol. 66, pp. 847875.

Vasilachis de Gialdino, Irene (1992): "El análisis lingüístico en la recolección e interpretación de materiales cualitativos", en Floreal H. Forni, María Antonia Gallart e Irene Vasilachis de Gialdino (eds.): Métodos cualitativos II. La práctica de la investigación, Buenos Aires: Centro Editor de América Latina.

- (2007): “Condiciones de trabajo y representaciones sociales", Discurso y Sociedad, vol. 1, n. 1, pp. 148-187.

Weber, M. (1979): Economía y Sociedad. Esbozo de sociología comprensiva, México: Fondo de Cultura Económica.

Wetlaufer, G. B. (1990): “Rhetoric and Denial in Legal Discourse”, Virginia Law Review, vol. 76, n. 8.

Zucker, L. (1999): “El papel de la institucionalización en la persistencia cultural”, en Walter W. Powell y Paul J. Dimaggio (comps.): El nuevo institucionalismo en el análisis organizacional, México: Fondo de Cultura Económica. 
